\title{
OPHTHALMODYNAMOMETRY IN CAROTID ARTERY DISEASE
}

\author{
BY \\ R. W. ROSS RUSSELL* and W. I. CRANSTON \\ From the Department of the Regius Professor of Medicine, University of Oxford
}

It is commonly believed that disease of the carotid artery may cause cerebral symptoms, although the way in which these come about is still uncertain.

The pressure changes in the upper part of the carotid artery are thus of great interest and may be approximately followed by measuring the ophthalmic artery pressure. This report is concerned with such measurements in different kinds of carotid disorder.

\section{Method}

The Baillart ophthalmodynamometer (dial type) was used and the technique of measurement has been discussed elsewhere (Hartmann, 1949). Readings were taken to the nearest $5 \mathrm{~g}$. The instrument was frequently recalibrated and a correction made for the weight of the plunger. The patients sat or lay supine and the systemic blood pressure was measured by the same observer with an arm cuff just before dynamometry. Apart from subconjunctival haemorrhage (one case) and corneal abrasion (one case), there were no complications. Patients with glaucoma, severe myopia, or retinal detachment were not examined.

\section{Results}

Normal Subjects.-Ophthalmic artery pressure (OAP) and systemic blood pressure (SBP) were measured in 98 adult subjects without signs or symptoms of cerebral or ocular disease. There were 63 patients in the age group 51 to 70 (106 eyes

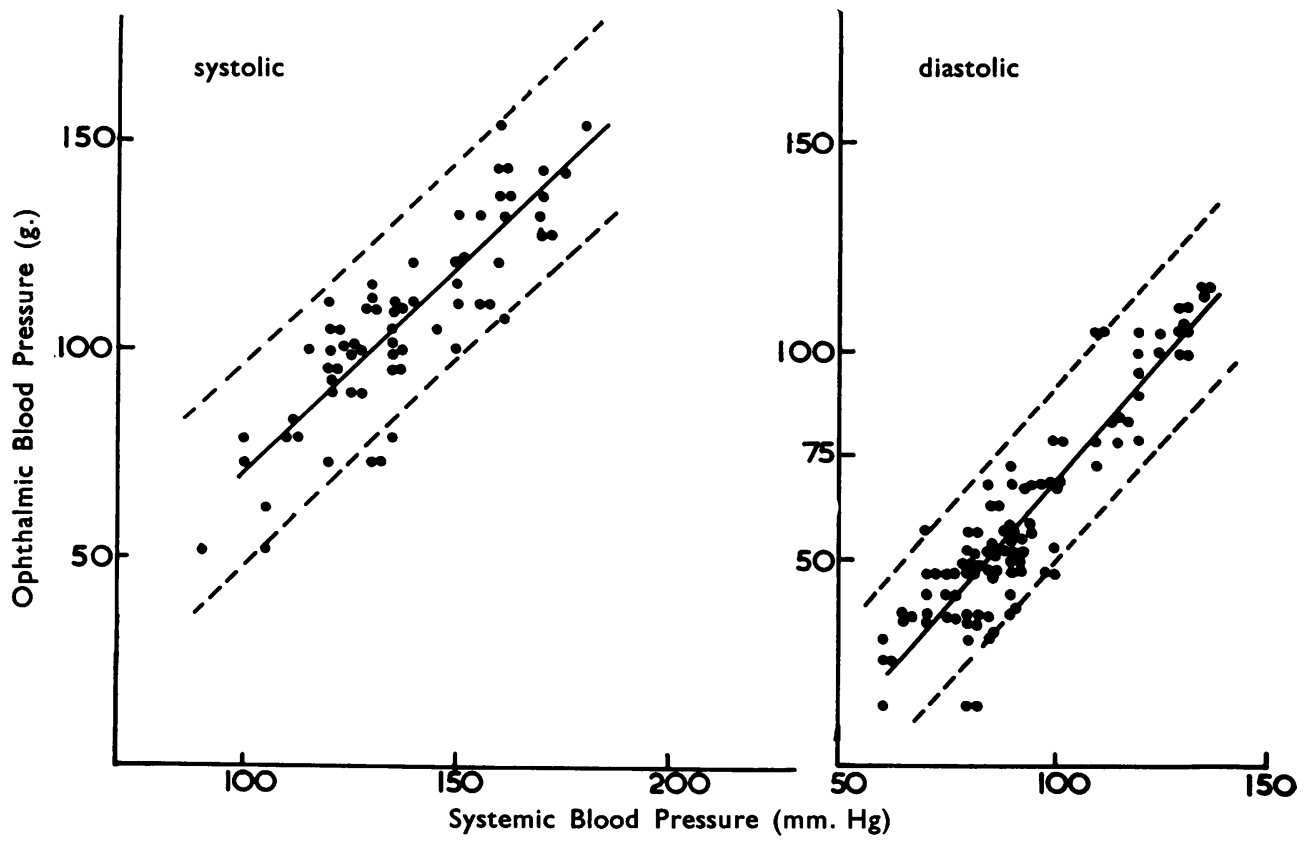

Fig. 1.-Relationship of OAP to BP in normal subjects over 50 years. The dotted lines show the $95 \%$ confidence limits.

${ }^{*}$ E. G. Fearnsides Scholar, University of Cambridge. 
Systolic

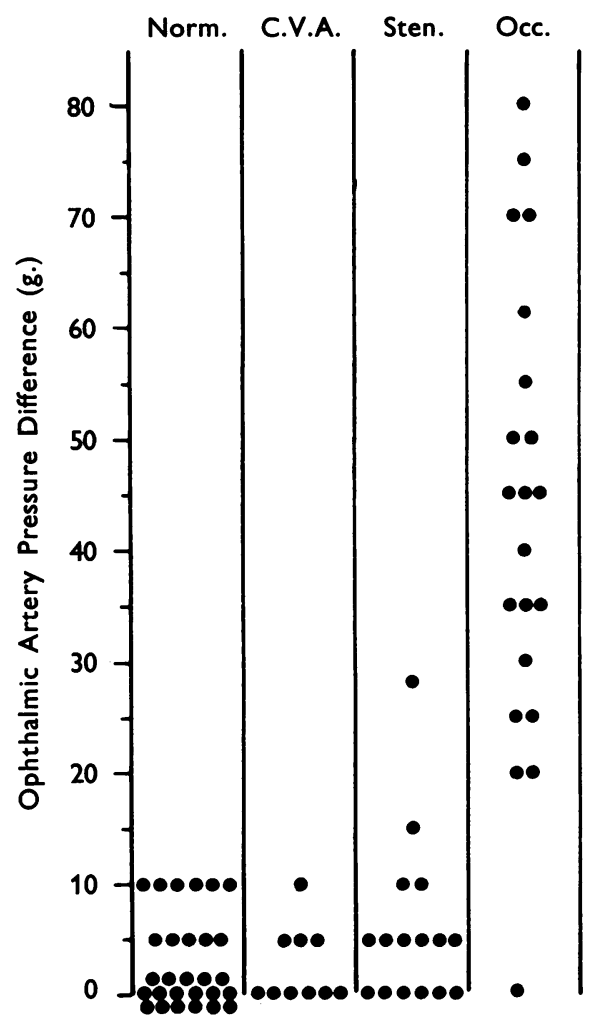

Diastolic

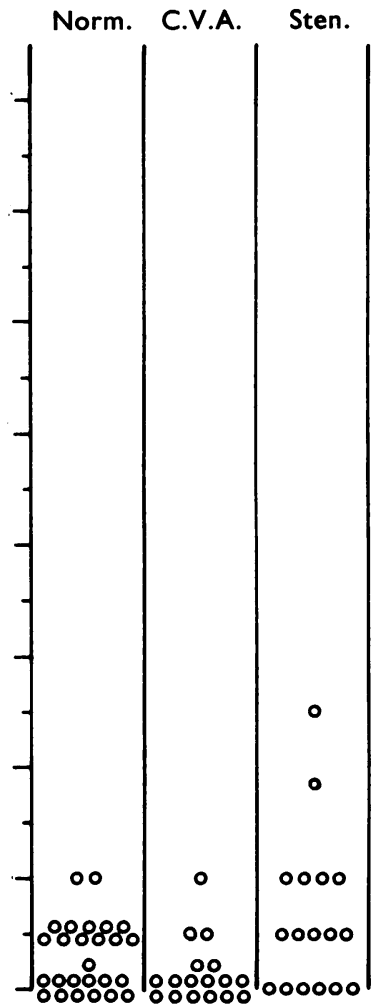

Occ.

00

0000

00

000

○8

oo

oo

o

FIG. 2-Differences in ophthalmic arterial pressure between two eyes in 28 normal patients, and in patients with cerebral vascular disease. Closed circles represent systolic levels, open circles diastolic levels.

examined) and 35 patients in the group 14 to 50 (45 eyes examined). The relationship between systemic and ophthalmic pressure in patients over 50 years of age is shown (Fig. 1) and is expressed by the equation OAP g. $=(\mathrm{SBP} \mathrm{mm} . \mathrm{Hg} \times 0.98)-26.8$ for systolic readings and OAP g. $=(\mathrm{SBP} \mathrm{mm} . \mathrm{Hg} \times$ 1.18) $-49 \cdot 1$ for diastolic readings. The slopes of the two regression lines are significantly different (variance ratio $5.33 ; p=<0.05$ ).

When patients under 50 are considered, the same difference between systolic and diastolic readings is apparent although the total numbers are less.

OAP g. $($ systolic $)=($ SBP mm. $\mathrm{Hg} \times 1.00)-31.2$

OAP g. $($ diastolic $)=($ SBP mm. $\mathrm{Hg} \times 0.83)-23.7$

Variance ratio $1 \cdot 25, \mathrm{p}=>0 \cdot 2$.

There is an insignificant difference between the younger and the older group when systolic slopes are compared. The diastolic slopes are different but this is probably due to the inclusion in the older group of a larger number of hypertensive subjects since the slopes do not differ significantly when older patients with diastolic pressures over $100 \mathrm{~mm}$. are excluded. This does not necessarily mean that the relationship OAP/SBP is different in those with hypertension but is due to the small scatter of bloodo pressure readings below $100 \mathrm{~mm}$.

There was good agreement between the pressures $\stackrel{\mathbb{Q}}{\circ}$ measured in the two eyes of individual patients, the $\overrightarrow{\vec{O}}$ difference, systolic or diastolic, being never more 3 than 10 g. (Fig. 2).

Cerebral Vascular Disease.-Ophthalmic artery pressures were measured in 15 patients recently admitted to hospital with a clinical diagnosis of cerebral thrombosis in whom angiography of the suspected carotid artery showed no abnormality. Ophthalmic artery pressures on both the sound andô the suspected side differed by less than $10 \mathrm{~g}$. and both were within normal limits when related to음 blood pressure (Fig. 3a).

Carotid Stenosis.-Seventeen patients with recent cerebral symptoms, either transient or permanent, $\sigma$ in whom angiography showed carotid stenosis weren examined in the same way. The majority of OAPN 


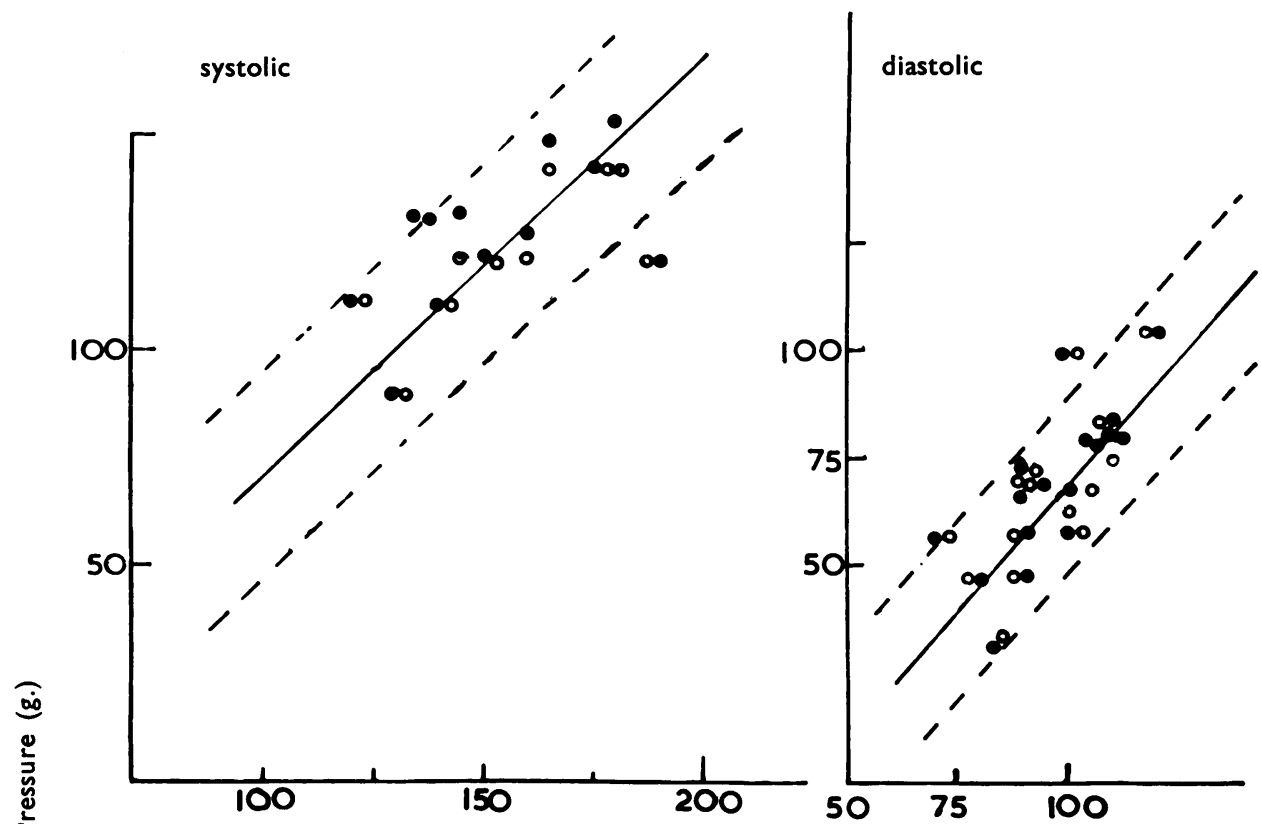

FIG. 3(a)

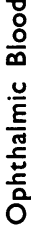
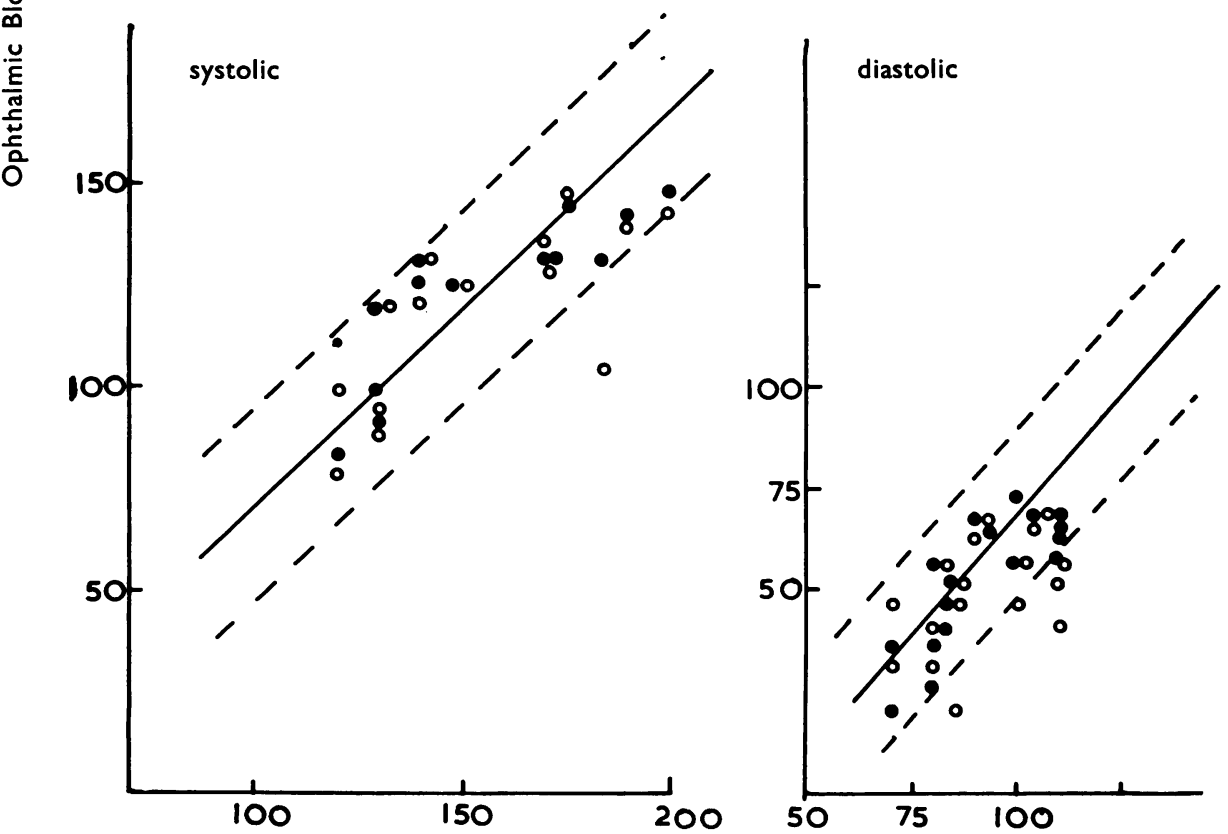

FIG. 3(b)

Systemic Blood Pressure (mm. Hg)

FIG. 3.-Relationship of OAP to BP in cerebral vascular disease (a) normal angiogram, (b) carotid stenosis, (c) carotid occlusion. Closed circles normal side. Open circles suspected side. Dotted lines show $95 \%$ confidence limits for normal subject over 50 . 

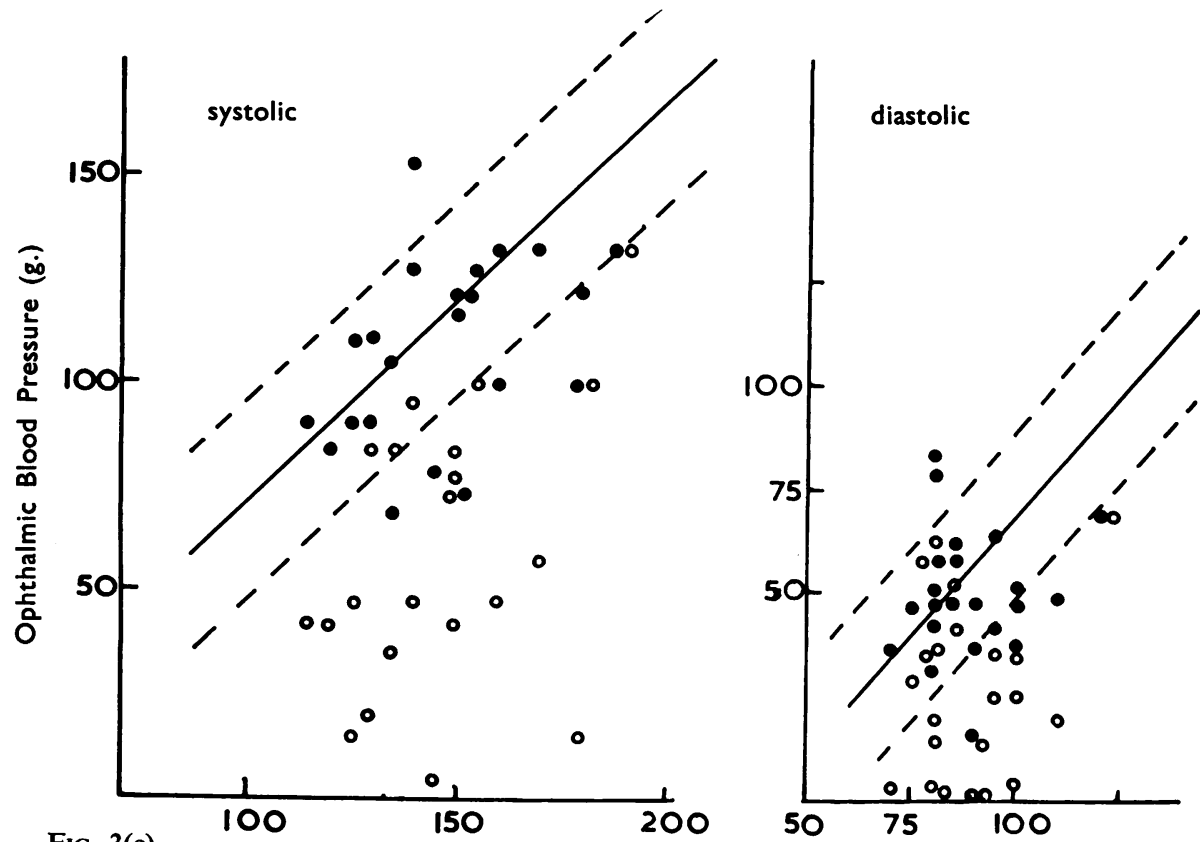

Fig. 3(c)
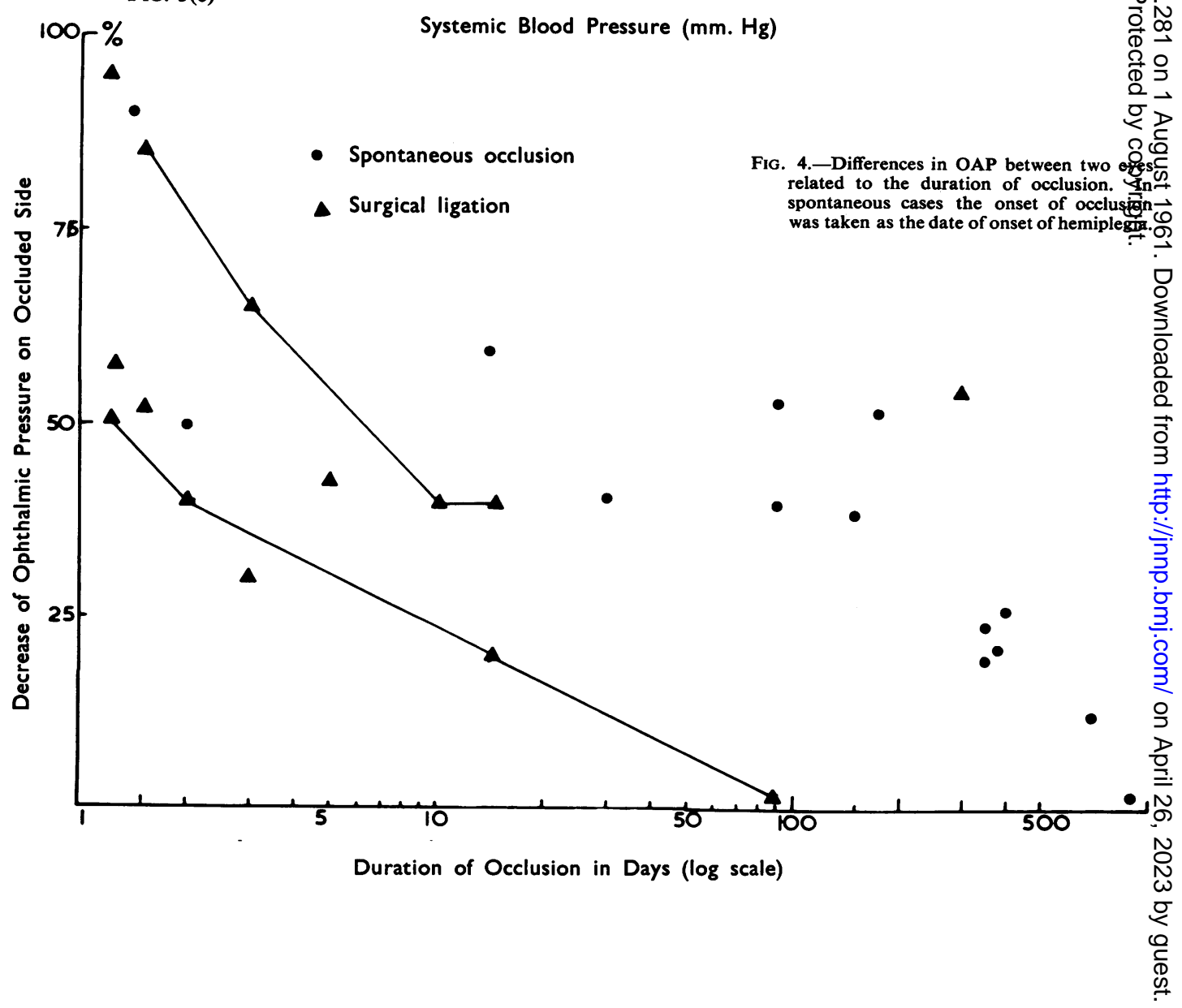
readings were within normal limits (Fig. $3 b$ ) and the difference between the two eyes of individual patients was less than $10 \mathrm{~g}$. in all but two cases $(15 \mathrm{~g}$. and $27 \mathrm{~g}$. systolic).

Carotid Occlusion.-Twenty-one patients with complete carotid occlusion were examined. Fourteen were cases of spontaneous internal carotid occlusion mostly with recent symptoms and seven had undergone common carotid ligation for intracerebral aneurysm. Ophthalmic systolic readings were abnormal in all but two cases but about a third of diastolic readings fell within the normal range (Fig. 3c). A comparison of pressures in the two eyes in most cases showed a difference of greater than $20 \mathrm{~g}$. systolic, the occluded side having the lower pressure. Diastolic differences were less marked. In general the greatest pressure differences were found in patients with very recent symptoms or immediately after carotid ligation. Longer standing cases showed less abnormality (Fig. 4) and a series of measurements on a patient after carotid ligation showed that the ophthalmic pressure returned to normal within three months, presumably as a result of increased collateral supply.

\section{Discussion}

Ophthalmodynamometry has many limitations, since it cannot allow for variations in intraocular tension, scleral rigidity, or the elasticity of retinal arteries. The intraocular tension is raised until blood flow is arrested and at this point it equals the pressure at the first proximal branch, i.e., the ophthalmic artery (Duke-Elder, 1926). Results in normal subjects show that the most important variant is systemic blood pressure and the relationship between eye and arm blood pressure are different from systolic and diastolic readings. There are several possible interpretations for this, but none is conclusive on the available evidence.

In Bailliart's hands (Bailliart, 1928) the reading for ophthalmic diastolic pressure in grams was equal to the diastolic systemic pressure in $\mathrm{mm}$. $\mathrm{Hg}$ and this was presumably achieved by calculating the appropriate area of the foot-plate pressing on the eye. In the present series the regression line relating ophthalmic to systemic pressure had a slope which approached unity but when extrapolated did not pass through zero but intersected the abscissa at about $25 \mathrm{~mm}$. The difference between these results and those of Bailliart and other workers (Bidault, 1931; Streiffe, Audéoud-Naville, and Audéoud, 1937) is probably due to minor variations in technique as in the arbitrary point taken as the diastolic level.

Previous reports on the value of ophthalmodyna-

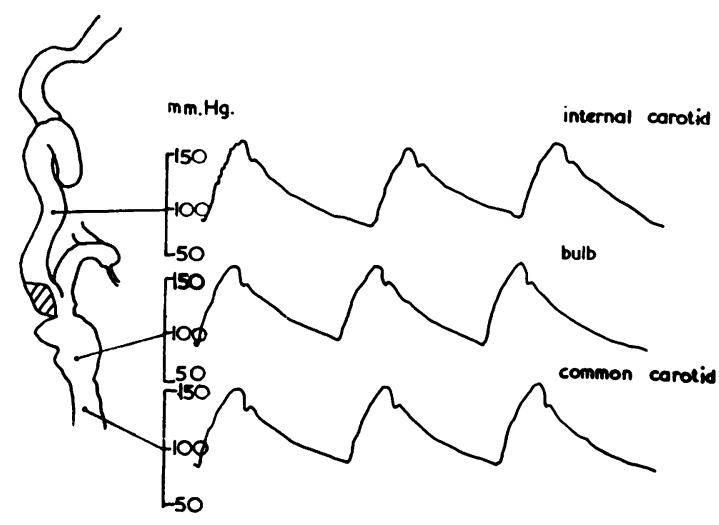

Fig. 5.-Pressure measurements taken at operation in a case of carotid stenosis. Readings were taken successively and not synchronously (Statham strain-gauge manometer).

mometry in detecting carotid occlusion are confirmed (Thomas and Petrohelos, 1953); Wood and Toole, 1957; Heyman, Karp, and Bloor, 1957). A difference in pressure of more than $25 \mathrm{~g}$. between the two eyes is almost diagnostic and a difference of this order is more likely to be found in systolic than in diastolic readings and in recent rather than late cases. The origin of the internal carotid artery may be explored on this evidence alone if angiography is not available. Conversely a small difference in ophthalmic pressure between the two sides in a proved case of complete carotid occlusion indicates that the obstruction has been present for some months and that surgery will probably be useless.

Milletti (1950) has shown that in cases of carotid occlusion where routine dynamometry shows no difference in pressure, compression of the patent carotid for 30 seconds produces a large fall in both eyes, more marked on the occluded side. This is too hazardous to become a routine procedure but compression for periods of a few seconds may be sufficient for diagnosis (Lowe and Stephens, 1961).

The normal findings in cases of carotid stenosis show that the flow through the damaged artery and through the collaterals is sufficient to maintain a normal pressure in the ophthalmic artery and probably in the upper part of the internal carotid (Duke-Elder, 1926). Direct measurement at operation confirms that in such cases there is only a slight pressure gradient across a stenosis (Fig. 5). This does not necessarily imply that blood flow through the stenosed segment is normal, since a normal pressure may be found with complete block in the presence of good collaterals.

Pressure measurements, both direct and indirect, are of interest in connexion with transient cerebral ischaemic attacks. These occur in various forms of 
cerebral vascular disease but are particularly associated with carotid stenosis. They are commonly thought to be the result of a fall in systemic blood pressure which produces a temporary vascular insufficiency in the territory of a damaged artery (Meyer, Fang, and Denny-Brown, 1954).

Clinical observations have shown this mechanism to operate in some patients (Shanbrom and Levy, 1957; Eastcott, Pickering, and Rob, 1954) but in others transient attacks seem to occur without change in pulse or blood pressure (Alajouanine, Lhermitte, and Gautier, 1960). Further, while large falls in blood pressure are frequently produced by treatment in hypertensive patients, many of whom also suffer from occlusive cerebral vascular disease, it is unusual for a focal ischaemic attack to occur (Fazekas, Kleh, and Parrish, 1955). If transient attacks are due to temporary falls of pressure in the carotid territory, and if the dynamometer reflects the pressure changes in the upper part of the artery, it would be expected that patients with a recent carotid occlusion who show a marked fall in ophthalmic pressure would suffer frequently from transient attacks.

In fact transient attacks are very rare after carotid ligation and are more often associated with carotid stenosis, and since there is no reason to suppose that falls in systemic blood pressure occur more frequently in carotid stenosis than occlusion, it seems that factors other than blood pressure may be operating. The observations of Fisher (1959) on a patient during an attack of monocular blindness and the effect of anticoagulant drugs on transient cerebral ischaemia
(Siekert and Millikan, 1955) have revived interest 耑 cerebral embolism, and more evidence on thes important point is needed.

\section{Summary}

Measurements of ophthalmic artery pressure and of systemic blood pressure were made in norma subjects and in patients with carotid stenosis an occlusion. A reduction in ophthalmic pressure wa found in recent cases of carotid occlusion but not in carotid stenosis. The significance of these finding with regard to the symptoms of carotid disease $\frac{\pi}{8}$ discussed.

I am indebted to Dr. W. Ritchie Russell, Mr. J. Pennybacker, and Professor Sir George Pickering f permission to report cases under their care.

\section{REFERENCES}

Alajouanine, T., Lhermitte, F., and Gautier, J. C. (1960). Neurol., 10 906.

Bailliart, P. (1928). Ann. Oculist. (Paris), 165, 321.

Bidault, R. (1931). Ibid, 168, 255.

Dastcott, H. H. G., Pickering, G. W., and Rob, C. G. (1954). Lance, 2, 994.

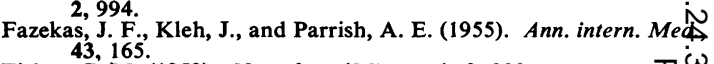

Fisher, C. M. (1959). Neurology (Minneap.), 9, 333.

Heyman, A., Karp, Trans. ophthal. Soc. U.K., 69, 123. (Minneap.), 7, 97.

Lowe, R. D., and Stephens, N. L. (1961). Lancet, 1, 1241.

Meyer, J. S., Fang, H. C., and Denny-Brown, D.' (1954) Arch. Neurol Psychiat. $72,296$.

Arch. Neurol. Psychiat., 72, 296.
Milletti, M. (1950). Acta neurochir. (Wien), 1, 196.
Shanbrom, E., and Levy, L. (1957). Amer. J. Med., 23, 197.

Siekert, R. G, and Millikan C. H. (1955). Proc. Mayo, Clin

Streiff, E. B., Audéoud-Naville, A., and Audéoud, R. (1937). Schơ med. Wschr., 67, 797.

Thomas, M. H., and Petrohelos, M. A. (1953). Amer. J. Ophrat.

Wood, F. A., and Toole, J. F. (1957). J. Amer. med. Ass., 165, 居69 